Article

\title{
Phase Evolution, Filler-Matrix Interactions, and Piezoelectric Properties in Lead Zirconate Titanate (PZT)-Filled Polymer-Derived Ceramics (PDCs)
}

\author{
Franziska Eichhorn ${ }^{1}$, Simone Kellermann ${ }^{1}$, Ulf Betke ${ }^{2}$ (D) and Tobias Fey ${ }^{1,3, *(D)}$ \\ 1 Institute of Glass and Ceramics, Department of Materials Science and Engineering, University of \\ Erlangen-Nürnberg, Martensstraße 5, 91058 Erlangen, Germany; franziska.eichhorn@fau.de (F.E.); \\ kellermann_simone@web.de (S.K.) \\ 2 Institute for Materials and Joining Technology-Nonmetallic Inorganic Materials and Composites, \\ Otto-von-Guericke-University Magdeburg, Große Steinernetischstraße 6, 39104 Magdeburg, Germany; \\ ulf.betke@ovgu.de \\ 3 Frontier Research Institute for Materials Science, Nagoya Institute of Technology, Nagoya 466-8555, Japan \\ * Correspondence: tobias.fey@fau.de
}

Received: 26 February 2020; Accepted: 23 March 2020; Published: 26 March 2020

\begin{abstract}
PZT-silsesquioxane-based 0-3 hybrid materials are prepared by mixing lead zirconate titanate $\left(\mathrm{Pb}(\mathrm{Zr}, \mathrm{Ti}) \mathrm{O}_{3} ; \mathrm{PZT}\right)$ powder with a $\left[\mathrm{R}-\mathrm{SiO}_{3 / 2}\right]_{\mathrm{n}}\left(\mathrm{R}=\mathrm{H}, \mathrm{CH}_{3}, \mathrm{CH}=\mathrm{CH}_{2}, \mathrm{C}_{6} \mathrm{H}_{5}\right)$ silsequioxane preceramic polymer. A PZT load up to $55 \mathrm{vol} \%$ can be reached in the final composite. The piezoelectric and mechanical properties are investigated as a function of the filler content and are compared with theoretical models and reference samples made of the pure preceramic polymer or PZT filler. The piezoelectric response of the composites, as expressed by the relative permittivity and the piezoelectric coefficients $\mathrm{d}_{33}$ and $\mathrm{g}_{33}$, increases with an increasing PZT content. The bending strength of the composites ranges between $15 \mathrm{MPa}$ and $31 \mathrm{MPa}$ without a clear correlation to the filler content. The thermal conductivity increases significantly from $0.14 \mathrm{~W} \cdot \mathrm{m}^{-1} \cdot \mathrm{K}^{-1}$ for the pure polymer-derived ceramic (PDC) matrix to $0.30 \mathrm{~W} \cdot \mathrm{m}^{-1} \cdot \mathrm{K}^{-1}$ for a sample containing $55 \mathrm{vol} \% \mathrm{PZT}$ filler. From X-ray diffraction experiments (XRD), specific interactions between the filler and matrix are observed; the crystallization of the PDC matrix in the presence of the PZT filler is inhibited; conversely, the PDC matrix results in a pronounced decomposition of the filler compared to the pure PZT material.
\end{abstract}

Keywords: piezoelectric material; polymer-derived ceramic (PDC); lead zirconate titanate (PZT); composite material; filler matrix interaction

\section{Introduction}

Transducers such as sensors and actuators based on piezoelectric ceramic-polymer composites (smart materials) offer a high potential for high tech systems [1]. These composite materials provide superior mechanical properties, such as elasticity, compared to conventional ceramic materials and can be optimized with respect to the piezoelectric properties as a function of the filler content. Due its high piezoelectric response and excellent electromechanical properties at the morphotropic phase boundary (MPB), lead zirconate titanate $\mathrm{Pb}\left(\mathrm{Zr}_{x} \mathrm{Ti}_{1-x}\right) \mathrm{O}_{3}$ (PZT) is mostly used as filler in these types of composite materials. $\mathrm{Pb}\left(\mathrm{Zr}_{x} \mathrm{Ti}_{1-x}\right) \mathrm{O}_{3}$ exists in three crystallographic polymorphs-tetragonal, rhombohedral, and cubic PZT [2] — whereas the phase stability depends on the temperature and Zr:Ti ratio, respectively. At the MPB the tetragonal and rhombohedral $\mathrm{Pb}\left(\mathrm{Zr}_{1-x} \mathrm{Ti}_{\mathrm{x}}\right) \mathrm{O}_{3}$ phases coexist [3] and the number of the polarization directions increases to 14 allowing an electrical-mechanical energy conversion 
efficiency up to $50 \%$ [2,4]. At room temperature the MPB in PZT is found for a Zr:Ti molar ratio of 53:47.

The properties of a composite material are determined by the number and the characteristics of the individual components as well as their composition and the connectivity between them. Newnham et al. introduced the concept of 0-3 connectivity, which describes isolated ceramic particles (no connectivity) filled into a three-dimensional polymer matrix (connectivity in all three spatial directions) [5]. Ceramic-polymer 0-3 hybrid materials feature several advantages in comparison to other composite materials: a simple and effective manufacturing process, tailored properties by varying the volume fraction of the ceramic filler and flexible control of shape by established polymer forming techniques.

A number of studies were published on 0-3 composites consisting of different polymers and piezoelectric ceramics $[1,6-10]$. All these composites are more flexible in comparison to the pure (piezoelectric) ceramic material. Piezocomposites are binary systems composed of piezoceramic filler particles with a dielectric constant $\varepsilon_{2}$ dispersed in a continuous polymer matrix with a dielectric constant $\varepsilon_{1}$, whereas $\varepsilon_{2}>\varepsilon_{1}$ [11]. With respect to the mechanical properties, this takes advantage of the flexibility and lower density of a polymer as a matrix, which is favorable for mechanical damping. However, polymers have a low dielectric constant, and, consequently, the piezoelectric response of the piezocomposite is a function of the amount of ceramic filler material $\Phi$ [11].

The combination of a small fraction of piezoelectric ceramic particles in a polymer matrix results in soft composites with limited piezoelectric properties. Moreover, the inter-connectivity of the piezoelectric particles is poor, and, hence, such composites show only a weak piezo electric effect. Heat generation at the PZT polymer interface, due to the friction between the filler and matrix, increases the passive damping at the cost of the mechanical energy. In addition, only a few polymer materials, such as polyvinylidenedifluoride (PVDF), possess a sufficient dielectric constant and dielectric strength to permeate the electric field necessary for the poling of the piezoelectric filler particles without dielectric breakdown and facilitating the active vibration damping composites [7,12].

In 0-3 ceramic-polymer composites, the (spherical) dielectric filler particles are dispersed in a continuous matrix material. The dielectric particles can be polarized by an external electrical field, whereas an individual particle can be represented by a single dipole moment. This dipole moment locally modifies the applied electrical field in the surrounding matrix medium. For small volume fractions of dielectric filler particles, equivalent to a long particle-particle distance, the mutual influence of the dipole moment of neighboring particles is negligible. Therefore, the prediction of field ratios by using the isolated sphere theory is physically reasonable. For increasing the amount of dielectric filler, it is no longer valid to ignore the cooperative effects between the electrical fields of neighboring particles [11]. Different models exist for the prediction of the piezoelectric properties of 0-3 composite materials, which usually include the permittivity of the individual matrix and filler phase as well as the volume fraction between filler and matrix, but ideally assume spherical particles [1]. A widely applied model from Yamada includes an anisotropy in particle shape and a distinct alignment of the piezoelectric filler particles along the electric field [10]. A model formulated by Jayasundere includes an interaction between neighbouring filler particles but on a basis of the assumption of the ideal spherical shape [11]. However, both models, Yamada and Jayasundere, are well suited to predict the piezoelectric properties of polymer-PZT composites $[1,13]$.

In this study, the processing and characterization of new 0-3 piezoelectric composites based on a preceramic silsesquioxane polymer is reported. Preceramic polymers can be shaped at a moderate temperature and subsequently crosslinked at temperatures between 100 and $150{ }^{\circ} \mathrm{C}$ into the respective thermoset. Further increasing the temperature to between 600 and $800{ }^{\circ} \mathrm{C}$ under inert atmosphere results in the loss of the organic moieties in the polymer backbone (pyrolysis) and the formation of an amorphous ceramic. At temperatures $>1000^{\circ} \mathrm{C}$, the amorphous ceramic starts to crystallize. Siloxane-based preceramic polymers result in the formation of SiOC ceramics initially, which finally crystallize into $\mathrm{SiO}_{2}$ and $\mathrm{SiC}$ [14]. 
Within this work, the volume fraction of the PZT filler is varied between 0 vol. $\%$ and 55 vol. \%, and, in addition, the influence of a pyrolysis temperature between 750 and $1250{ }^{\circ} \mathrm{C}$ is investigated. The experimental results for the piezoelectric parameters relative permittivity, and piezoelectric charge constant $d_{33}$ were compared with the results from the theoretical models of Yamada, Jayasundere, and Lichtenecker $[1,2,10,11,13]$. Mechanical properties such as bending strength as well as the thermal conductivity were measured and analyzed in dependence of the filler content of the sample and heat treatment processing.

\section{Materials and Methods}

\subsection{Sample Preparation}

The PZT-powder (NCE51, Noliac Ceramics s.r.o., Livrice, Czech Republic; particle size: $1.8 \mu \mathrm{m}$, see Figure S3, Supporting Information) was heat treated at $700{ }^{\circ} \mathrm{C}$ for $2 \mathrm{~h}$ in air for debinding. Afterwards, 32 vol.\% of debinded PZT powder was dispersed in a solution of 0.2 vol.\% stearic acid (Riedel de Haen, Seelze, Germany) in 67.8 vol.\% n-hexane (Merck KGaA, Darmstadt, Germany). The resulting mixture was roller-milled for $24 \mathrm{~h}$. Afterwards, the hydrophobized PZT powder was obtained by the evaporation of the solvent and final drying at $160{ }^{\circ} \mathrm{C}$ for $6 \mathrm{~h}$. To produce the $0-3 \mathrm{PZT}$-silsesquioxane hybrid materials, the hydrophobized PZT powder was mixed with the preceramic polymer SILRES H62C (Wacker Chemie AG, Burgdorf, Germany) using the vacuum stirrer Koala (Mestra, Passau, Germany). The mass obtained after vacuum mixing was degassed and homogenized in the vacuum mixer for $30 \mathrm{~min}$. H62 $\mathrm{C}$ is a silsesquioxane oligomer with the general composition $\left[\mathrm{R}-\mathrm{SiO}_{3 / 2}\right]_{\mathrm{n}}(\mathrm{R}=\mathrm{H}$, $\mathrm{CH}_{3}, \mathrm{CH}=\mathrm{CH}_{2}, \mathrm{C}_{6} \mathrm{H}_{5}$ ) and contains $\equiv \mathrm{Si}-\mathrm{H}$ as well as $\equiv \mathrm{Si}-\mathrm{CH}=\mathrm{CH}_{2}$ moieties. The crosslinking can be performed at moderate temperature by a hydrosilylation reaction; the necessary platinum catalyst is included in the H62C material.

The amount of PZT in the mass was varied between 0 and 55 vol.\%, whereas mixtures with a filler content larger than 50 vol.\% were kneaded in a roller mill (EXAKT Advanced Technologies GmbH, Norderstedt, Germany). Finally, the homogenized and degassed PZT-H62C mixture was filled into self-made silicon molds (Elastosil M 4643 A+B, Wacker Chemie AG, Burgdorf, Germany). The curing of the PZT-H62C mixture was performed at $140{ }^{\circ} \mathrm{C}$ for 3 to $6 \mathrm{~h}$. After demolding, the samples were heated to $200{ }^{\circ} \mathrm{C}$ for $5 \mathrm{~h}$. The selected samples were finally pyrolyzed in Ar atmosphere at 750 or $1250{ }^{\circ} \mathrm{C}$, respectively, for $2 \mathrm{~h}$. To avoid the evaporation of $\mathrm{PbO}$ from the PZT filler during the heat treatment, the samples were heated together with a mixture of $\mathrm{PbO}, \mathrm{ZrO}_{2}$ and $\mathrm{PbZrO}_{3}$ in a closed crucible.

The reference samples made of the pure PZT ceramic were prepared by injection molding from a mass containing 48.1 vol.\% PZT, 47.2 vol.\% carnauba wax (Carl Roth GmbH, Karlsruhe, Germany), and 4.7 vol.\% Granopent paraffin (Carl Roth $\mathrm{GmbH}$, Karlsruhe, Germany). The samples without PZT filler were prepared by crosslinking and pyrolyzing pure H62C at the conditions stated previously.

\subsection{Metallization and Polarization of the Samples}

For the characterization of the piezoelectric response, the samples were cut into two different geometries: rod-like specimens with a length:width:height ratio of 13:3:1 and cylindrical samples with a diameter:height ratio of 10:1. The top and bottom faces were polished using a 3- $\mu$ m diamond dispersion and were subsequently metallized by coating with conductive silver (Acheson Silber DAG 1415, Plano GmbH, Wetzlar, Germany). After drying, the metallized samples were put in between two copper electrodes and placed into a silicone oil bath (Wacker Chemie AG, Burgdorf, Germany). The polarization was performed at a temperature of $130{ }^{\circ} \mathrm{C}$ and the electric field was increased within $30 \mathrm{~min}$ to a final strength of $2 \mathrm{kV} \cdot \mathrm{mm}^{-1}$. Afterwards, the samples were cooled to room temperature within three hours while keeping the electric field constant. The optimal polarization conditions required for the PZT-polymer composite materials within this work were estimated by the Kura Kawa theory $[7,15]$. 


\subsection{Sample Characterization}

The analysis of the sample microstructure was performed by scanning electron microscopy with an acceleration voltage of $25 \mathrm{kV}$ (SEM, Quanta 2000, FEI, Hillsboro, OR, USA) after grinding the specimen surface with 180-, 600-, 2000-grit SiC paper and polishing with a 3- $\mu \mathrm{m}$ diamond dispersion. The quantitative phase composition in the composite materials was analyzed by powder X-ray diffraction, XRD (D500 diffractometer, Siemens AG, Karlsruhe, Germany) using copper K $\alpha_{1} / \alpha_{2}$ radiation after ball-milling the respective sample for $5 \mathrm{~min}$ at $300 \mathrm{rpm}$. The grinded powder was filled into a backloading sample holder and measured in a $\theta / \theta$ reflection geometry with a $2 \theta$ range from $5^{\circ}$ to $70^{\circ}$. The obtained diffraction patterns were analyzed by the Rietveld technique using the Topas Academic 5 package (Coelho Software, Brisbane, Australia).

The thermogravimetric analysis of selected PZT-polysilsesquioxane composites was carried out up to $1300{ }^{\circ} \mathrm{C}$ with a heating rate of $5 \mathrm{~K} / \mathrm{min}$ under flowing Nitrogen using a STA429 device (Netzsch GmbH, Selb, Germany). Prior to the sample investigation, a correction thermogravimetry (TG) curve was recorded with the respective empty alumina crucible, which was subtracted from the final measurement.

The pycnometric sample density was determined by He pycnometry (AccuPyc II 1340, Micromeritics, Norcross, GA, USA) and compared to the geometric density of the samples. The total porosity of the specimens was calculated from the ratio of geometric density and pycnometric density.

The bending strength was determined on bars with $2 \times 2.5 \times 25 \mathrm{~mm}^{3}$ by the four-point bending test using an Instron Model 5565 testing machine (Instron GmbH, Pfungstadt, Germany). For each sample series, 15 specimens were measured and the bending strength $\sigma_{f}$ was calculated from the fracture force $F$, the sample width $b$ and height $h$, and the distance between the four rolls of the four-point bending setup ( $l=$ top, $L=$ bottom) according to Equation (1):

$$
\sigma_{f}=\frac{3 \times F \times(L-l)}{2 \times b \times h}
$$

The average bending strength was calculated by the Maximum Likelihood method.

The thermal conductivity of the composite materials was determined on cylindrical samples by the hot-plate method at a temperature difference of $20 \mathrm{~K}\left(40^{\circ} \mathrm{C}\right.$ hot plate temperature against room temperature). For each sample series, five specimens were measured and averaged. The collected data were compared to theoretical values estimated by the Landauer model based on the effective percolation theory $[16,17]$.

For the characterization of the piezoelectric properties of the samples, the relative permittivity as well as the charge constant $d_{33}$ were determined using the Berlincount method with a piezometer PM 300 at a fixed frequency of $110 \mathrm{~Hz}$ (Piezo Test, London, UK). The sample was mounted between the oscillating contact pads of the measurement device with a contact force of $2 \mathrm{~N}$. The experimental results were compared with theoretical permittivity values calculated by the Yamada model for anisotropic particles [10], the model of Jayasundere [11], and the model of Lichtenecker [1].

\section{Results and Discussion}

\subsection{Microstructure Evolution in PZT-Polymer and PZT-PDC Composites}

From SEM micrographs, the formation of a percolating network of PZT filler particles in the samples cured at $200{ }^{\circ} \mathrm{C}$ is observed for PZT loads exceeding 50 vol.\% (Figure S1, Supporting Information). For lower volume fractions of PZT, the individual particles are separated through the polymer matrix material without interconnection between the filler species (Figure 1a). The mean particle diameter of the PZT filler in the composite samples crosslinked at $200^{\circ} \mathrm{C}$ is $1.8 \mu \mathrm{m}$. 


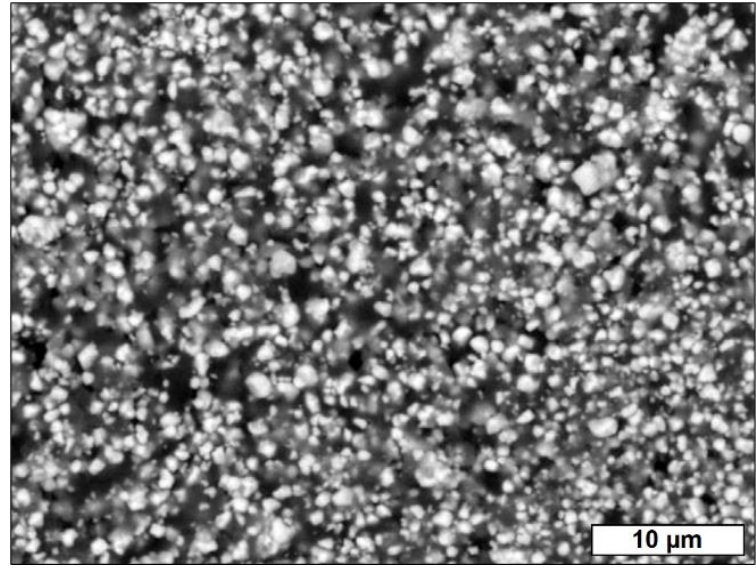

(a)

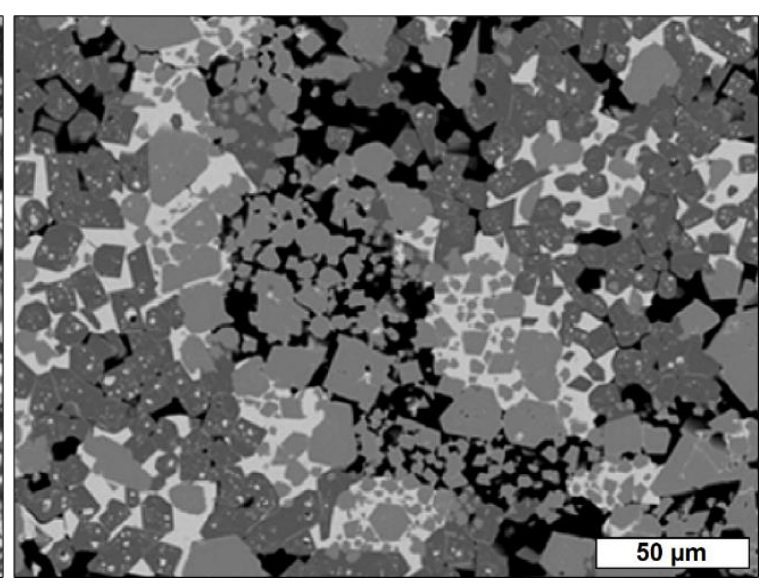

(b)

Figure 1. Scanning electron microscopy (SEM) micrographs of selected $\mathrm{Pb}(\mathrm{Zr}, \mathrm{Ti}) \mathrm{O}_{3}$ (PZT)-polymer composites with a filler content of $40 \mathrm{vol}$ \% PZT (a) after the crosslinking of the silsesquioxane resin at $200{ }^{\circ} \mathrm{C}$ and (b) after heat treatment processing at $1250{ }^{\circ} \mathrm{C}$.

During the heat treatment of the composites at elevated temperatures between 500 and $1250{ }^{\circ} \mathrm{C}$, microstructural changes are observed (Figure S2, Supporting Information). The ceramization of the pure $\mathrm{H} 62 \mathrm{C}$ preceramic polymer occurs in two subsequent steps in the temperature range between 400 and $900{ }^{\circ} \mathrm{C}$ according to thermogravimetry (TG) analyses (Figure 2), whereas the pure H62C preceramic polymer gives a ceramic yield of approximately $62 \mathrm{wt} \%$. The presence of the PZT filler particles changes the decomposition behavior of the preceramic polymer; the ceramization now takes place in four consecutive reactions in the temperature range between 400 and $750{ }^{\circ} \mathrm{C}$. Consequently, the PZT filler alters the decomposition reactions in the PDC matrix, resulting in a complete ceramization at a temperature $150{ }^{\circ} \mathrm{C}$ lower than for the pure $\mathrm{H} 62 \mathrm{C}$ material. After thermal treatment at 500 and $750{ }^{\circ} \mathrm{C}$, the microstructure of the samples is similar to the structure of the initial composites crosslinked at $200{ }^{\circ} \mathrm{C}$. Nevertheless, the matrix phase is made up of a mixture of polymer and already formed amorphous PDC material. With respect to the size and shape of the PZT filler particles, no significant changes were observed.

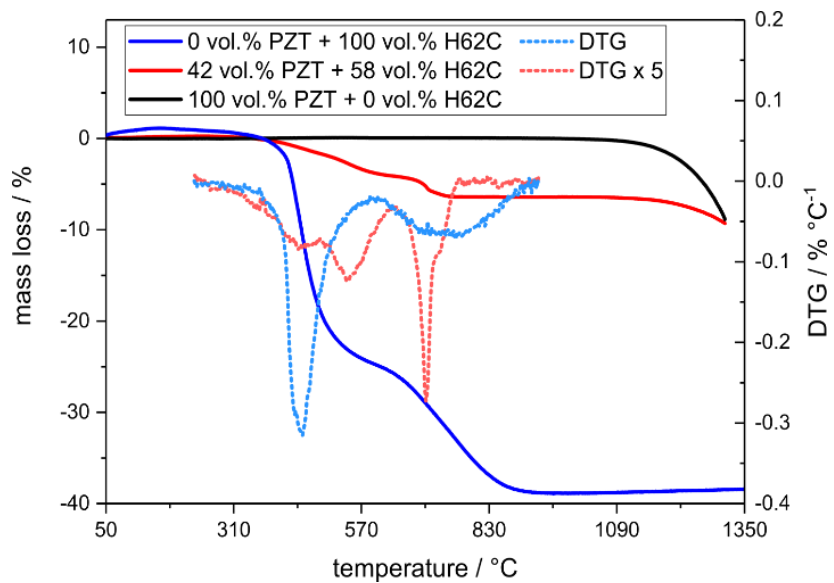

Figure 2. Thermogravimetry of the pure, hydrophobized PZT powder (black line), a composite material containing 42 vol.\% PZT (red line) and of the pure H62C silsesqioxane polymer (blue line). The dotted lines show the first derivative of the respective thermogravimetry data (DTG).

The pure PZT filler is stable up to approximately $1000{ }^{\circ} \mathrm{C}$ with respect to the TG data; no significant weight change is observed. However, in the temperature regime between 1000 and $1300{ }^{\circ} \mathrm{C}$, 
a weight loss of $9 \mathrm{wt} . \%$ is observed as a consequence of the decomposition of the PZT powder due to the evaporative loss of $\mathrm{PbO}$ [18].

From the SEM micrographs, a significant grain growth of the filler particles is observed for a heat treatment at $1000^{\circ} \mathrm{C}$ and especially at $1250{ }^{\circ} \mathrm{C}$ (Figure S2; Supporting Information). For a pyrolysis at $1250^{\circ} \mathrm{C}$, at least three separate phases are formed with respect to the grey levels within the SEM image (Figure 1b). This is in agreement with the TG results, which indicate a decomposition of the PZT phase above $1000^{\circ} \mathrm{C}$.

The porosity, as determined by the ratio of the geometric sample density and the pycnometric bulk density of the material, ranges between 2.4 vol.\% and 5.6 vol.\% for the PZT-silsesquioxane composites crosslinked at $200{ }^{\circ} \mathrm{C}$ (Figure 3). For filler loads between 5 and 35 vol.\%, no significant variation in the porosity is detected with an average of 3.1 vol.\%. However, in samples with a PZT load above $35 \mathrm{vol} . \%$, the porosity increases significantly up to $5.6 \mathrm{vol} . \%$ for the specimen containing $50 \mathrm{vol} . \%$ PZT filler. This increase in porosity is correlated to the increasing difficulty in homogenization and especially the degassing of the initial PZT-H62C mixture for high filler loads.

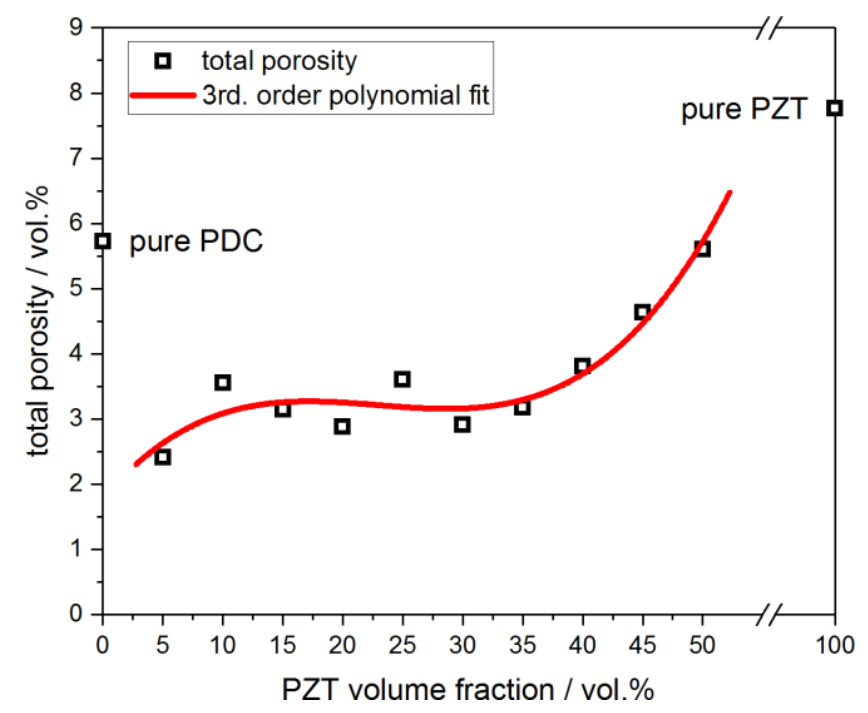

Figure 3. Porosity of the PZT-polymer composites crosslinked at $200{ }^{\circ} \mathrm{C}$ as a function of the PZT filler volume fraction.

\subsection{Phase Evolution in PZT-Polymer and PZT-PDC Composites}

The phase composition of the composite samples has been determined as a function of the filler load and the pyrolysis temperature by powder XRD and Rietveld analysis. The results are summarized in Table 1. The diffractograms of selected samples are shown in Figure 4, together with the corresponding Rietveld fits. The $\mathrm{Zr}$ concentration $x$ in the respective $\mathrm{Pb}\left(\mathrm{Zr}_{x} \mathrm{Ti}_{1-x}\right) \mathrm{O}_{3}$ phases has been determined from their unit cell volume by applying Vegard's law [19] on structural data for rhombohedral and tetragonal PZT from the literature [20-24]. From this linear relationship, the $\mathrm{Zr}$ content $x$ in the PZT filler of the respective sample could be estimated (Figure 5).

The pure PZT filler consists of a mixture of rhombohedral $\mathrm{Pb}\left(\mathrm{Zr}_{x} \mathrm{Ti}_{1-x}\right) \mathrm{O}_{3}(39 \mathrm{wt} . \%)$ and tetragonal $\mathrm{Pb}\left(\mathrm{Zr}_{x} \mathrm{Ti}_{1-x}\right) \mathrm{O}_{3}(61 \mathrm{wt} . \%)$, and, for both phases, a $\mathrm{Zr}$ content of $x=0.50$ has been determined after a heat treatment at $200^{\circ} \mathrm{C}$. This is in good accord with a (commercial) PZT material close to the MPB with an optimized electrical-mechanical energy conversion efficiency [3,4]. The pure polymer matrix crosslinked at $200{ }^{\circ} \mathrm{C}$ is completely amorphous. The crystallization of the PDC is observed for a specimen without PZT filler heat treated at $1250^{\circ} \mathrm{C}$; in this case, $\mathrm{SiO}_{2}$, as the cristobalite polymorph, is only detected in the crystalline phase. 
Table 1. Phase composition and chemical composition of the individual PZT fillers for selected PZT-polymer and PZT-SiOC composites (r-PZT: rhombohedral $\mathrm{Pb}\left(\mathrm{Zr}_{x} \mathrm{Ti}_{1-x}\right) \mathrm{O}_{3} ; \mathrm{t}-\mathrm{PZT}$ : tetragonal $\left.\mathrm{Pb}\left(\mathrm{Zr}_{x} \mathrm{Ti}_{1-x}\right) \mathrm{O}_{3}\right)$. The $\mathrm{Zr}$ content $x$ and the Ti content $(1-x)$ in the $\mathrm{Pb}\left(\mathrm{Zr}_{x} \mathrm{Ti}_{1-x}\right) \mathrm{O}_{3}$ filler is calculated by Vegard's law from the unit cell volume $\mathrm{V}$ and applied in the respective Rietveld analyses.

\begin{tabular}{|c|c|c|c|c|c|c|c|c|c|}
\hline \multicolumn{2}{|c|}{ Sample } & \multicolumn{8}{|c|}{ Phase Content and Chemical Composition of $\mathrm{Pb}\left(\mathrm{Zr}_{x} \mathrm{Ti}_{1-x}\right) \mathrm{O}_{3}(\mathrm{PZT})$ Filler } \\
\hline $\begin{array}{c}\text { filler } \\
\text { content/wt.\% }\end{array}$ & $\begin{array}{c}\text { pyrolysis } \\
\mathrm{T} /{ }^{\circ} \mathrm{C}\end{array}$ & r-PZT/wt.\% & $\mathrm{V}_{\mathrm{r}-\mathrm{PZT}} / \AA^{3}$ & $\operatorname{Zr} \operatorname{content} x$ & t-PZT/wt.\% & $\mathrm{V}_{\mathrm{t}-\mathrm{PZT}} / \AA^{3}$ & $\mathrm{Zr}$ content $x$ & $\mathrm{~m}-\mathrm{ZrO}_{2} / \mathrm{wt} . \%$ & cristobalite/wt.\% \\
\hline 50 & 200 & $29 \pm 1.4$ & $408.5 \pm 0.2$ & $0.534 \pm 0.004$ & $71 \pm 1.4$ & $67.60 \pm 0.03$ & $0.522 \pm 0.003$ & $-/-$ & $-/-$ \\
\hline 50 & 750 & $34 \pm 2.4$ & $408.2 \pm 0.3$ & $0.524 \pm 0.007$ & $66 \pm 2.4$ & $67.53 \pm 0.04$ & $0.515 \pm 0.005$ & $-/-$ & $-/-$ \\
\hline 50 & 1250 & $-/-$ & $-/-$ & $-/-$ & $19 \pm 0.3$ & $63.70 \pm 0.01$ & $0.096 \pm 0.001$ & $81 \pm 0.3$ & $-/-$ \\
\hline 50 & 200 & $33 \pm 1.0$ & $408.2 \pm 0.2$ & $0.528 \pm 0.004$ & $67 \pm 1.0$ & $67.58 \pm 0.02$ & $0.520 \pm 0.002$ & $-/-$ & $-1-$ \\
\hline 100 & 200 & $38.7 \pm 0.5$ & $407.0 \pm 0.6$ & $0.502 \pm 0.013$ & $61.3 \pm 0.5$ & $67.40 \pm 0.01$ & $0.501 \pm 0.001$ & $-/-$ & $-/-$ \\
\hline 0 & 1250 & $-/-$ & $-/-$ & $-/-$ & $-/-$ & $-/-$ & $-/-$ & $-/-$ & $100^{\mathrm{a}}$ \\
\hline 50 & 1250 & $-/-$ & $-/-$ & $-/-$ & $18.1 \pm 0.2$ & $63.69 \pm 0.01$ & $0.095 \pm 0.001$ & $81.9 \pm 0.2$ & $-/-$ \\
\hline 100 & 1250 & $1.3 \pm 0.2$ & $385.0 \pm 0.5$ & $0.02 \pm 0.01$ & $59.5 \pm 0.5$ & $64.92 \pm 0.01$ & $0.229 \pm 0.001$ & $39.2 \pm 0.5$ & $-/-$ \\
\hline
\end{tabular}

${ }^{\mathrm{a}}$ of the crystalline fraction; a broad maximum below $18^{\circ}$ indicates a significant amount of amorphous material. 


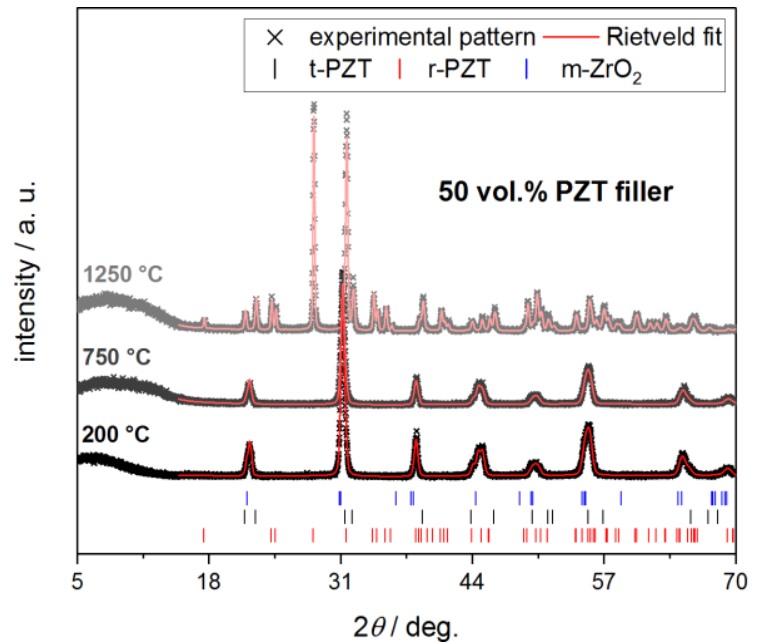

(a)

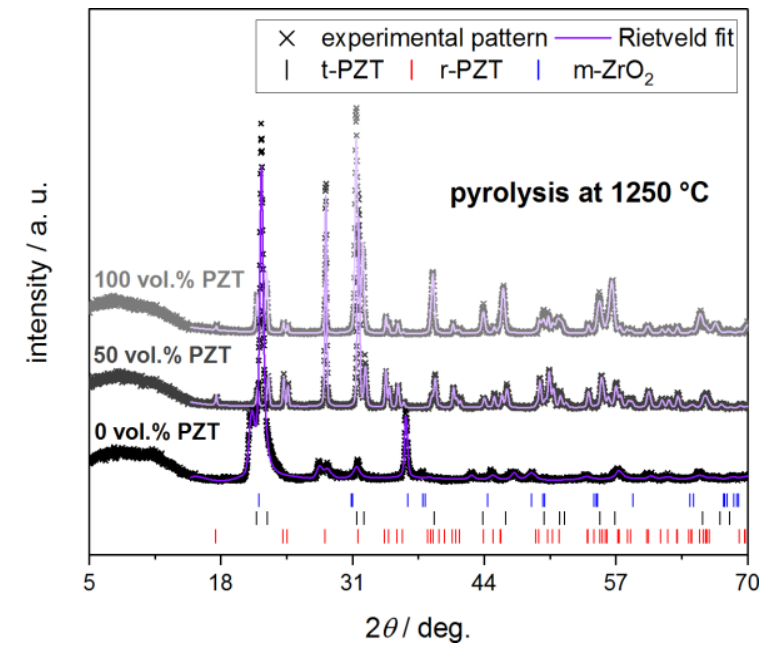

(b)

Figure 4. Powder XRD patterns for PZT-polymer and PZT-PDC composites together with the corresponding Rietveld fits. (a) The variation in the heat treatment temperature at a constant PZT load of 50 vol.\%; (b) the variation in the PZT volume fraction for a pyrolysis temperature of $1250{ }^{\circ} \mathrm{C}$.

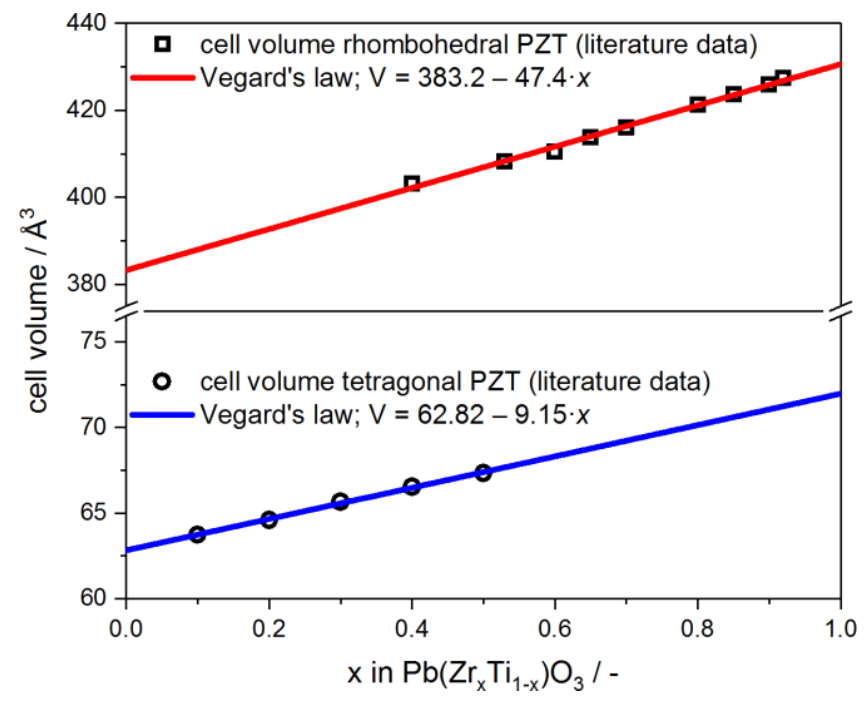

Figure 5. Literature data of the unit cell volume as a function of the $\mathrm{Zr}$ content $x$ in rhombohedral ( $\square$ ) and tetragonal $\mathrm{Pb}\left(\mathrm{Zr}_{x} \mathrm{Ti}_{1-x}\right) \mathrm{O}_{3}(\bigcirc)$. The data were fitted by Vegard's law, which was subsequently applied in determining the $\mathrm{Zr}$ content $x$ in the PZT filler from its unit cell volume.

For the composite samples containing 50 vol.\% of PZT filler, which were heat treated at 200 and $750{ }^{\circ} \mathrm{C}$, respectively, no significant changes in the phase composition are detected. The PZT filler remains stable under these conditions and is still comprised of a mixture of rhombohedral and tetragonal $\mathrm{Pb}\left(\mathrm{Zr}_{x} \mathrm{Ti}_{1-x}\right) \mathrm{O}_{3}$ with a $\mathrm{Zr}$ content $x$ in a tight range between 0.515 and 0.534 for both phases. Consequently, neither filler decomposition nor the detrimental interactions between the PZT filler and the PDC matrix occur.

This behavior changes significantly for samples heat treated at a temperature of $1250{ }^{\circ} \mathrm{C}$. For the pure PZT filler, a decomposition reaction accompanied by the formation of $39 \mathrm{wt}$. $\%$ monoclinic $\mathrm{ZrO}_{2}$ is observed. Only traces of $1 \mathrm{wt}$.\% are detected for the rhombohedral polymorph of $\mathrm{Pb}\left(\mathrm{Zr}_{x} \mathrm{Ti}_{1-x}\right) \mathrm{O}_{3}$ and the phase content of the tetragonal $\mathrm{Pb}\left(\mathrm{Zr}_{x} \mathrm{Ti}_{1-x}\right) \mathrm{O}_{3}$ amounts to $60 \mathrm{wt}$.\%. However, the unit cell volume of $64.9 \AA^{3}$ for the tetragonal $\mathrm{Pb}\left(\mathrm{Zr}_{x} \mathrm{Ti}_{1-x}\right) \mathrm{O}_{3}$ phase is significantly smaller compared to the initial PZT filler material $\left(67.4 \AA^{3}\right)$. This indicates a considerable depletion of $\mathrm{Zr}$ in the $\mathrm{Pb}\left(\mathrm{Zr}_{x} \mathrm{Ti}_{1-x}\right) \mathrm{O}_{3}$ phase, which could be quantified to a Zr content $x$ of 0.23 according to Vegard's law. This is in good agreement 
to the depletion of the rhombohedral polymorph of $\mathrm{Pb}\left(\mathrm{Zr}_{x} \mathrm{Ti}_{1-x}\right) \mathrm{O}_{3}$, which is the stable phase only for higher $\mathrm{Zr}$ contents $x$. The driving force of the $\mathrm{Pb}\left(\mathrm{Zr}_{x} \mathrm{Ti}_{1-x}\right) \mathrm{O}_{3}$ decomposition is the volatization of lead(II)-oxide, PbO, which is known to occur for PZT materials at an elevated temperature [18]. Consequently, the decomposition reaction of the PZT material can be formulated according to Equation (2) by introducing a conversion factor $z$, which is the amount of released $\mathrm{PbO}$. In addition, it is assumed that the decomposition reaction yields $\mathrm{ZrO}_{2}$ rather than $\mathrm{TiO}_{2}$, as no separate, binary titanium-oxygen phase is observed in the Rietveld analyses:

$$
\mathrm{PbZr}_{x} \mathrm{Ti}_{1-x} \mathrm{O}_{3} \rightarrow(1-z) \mathrm{PbZr}_{(x-z) /(1-z)} \mathrm{Ti}_{(1-x) /(1-z)} \mathrm{O}_{3}+z \mathrm{PbO} \uparrow+z \mathrm{ZrO}_{2}
$$

For the PZT material treated at $1250{ }^{\circ} \mathrm{C}$ with an initial $x=0.5$, a conversion factor $z=0.35$ is in good agreement with the $\mathrm{Zr}$ content of 0.23 , as calculated from the XRD data for the $\mathrm{Pb}\left(\mathrm{Zr}_{x} \mathrm{Ti}_{1-x}\right) \mathrm{O}_{3}$ phase. However, if the expected weight fractions of $\mathrm{Pb}\left(\mathrm{Zr}_{0.23} \mathrm{Ti}_{0.77}\right) \mathrm{O}_{3}$ and $\mathrm{ZrO}_{2}$ are calculated under consideration of Equation (2), the amount of $\mathrm{ZrO}_{2}$ is clearly underestimated. This can be justified by the formation of significant amounts of amorphous material, which could be either non-crystalline $\mathrm{Pb}\left(\mathrm{Zr}_{0.23} \mathrm{Ti}_{0.77}\right) \mathrm{O}_{3}$ or amorphous $\mathrm{TiO}_{2}$ formed by further $\mathrm{PbO}$ loss from the $\mathrm{Pb}\left(\mathrm{Zr}_{0.23} \mathrm{Ti}_{0.77}\right) \mathrm{O}_{3}$ phase. The phase composition determined by Rietveld analysis (39 wt.\% $\mathrm{ZrO}_{2}$ and $\left.61 \mathrm{wt} . \% \mathrm{~Pb}\left(\mathrm{Zr}_{x} \mathrm{Ti}_{1-x}\right) \mathrm{O}_{3}\right)$ can be explained by assuming a decomposition according to Equation (2) and the formation of a $\mathrm{Pb}\left(\mathrm{Zr}_{0.23} \mathrm{Ti}_{0.77}\right) \mathrm{O}_{3}$ phase, which consists of $67 \%$ of non-crystalline material.

For the PZT-PDC composite material with an initial filler load of 50 vol.\% and heat treated at $1250{ }^{\circ} \mathrm{C}$, the phase evolution differs significantly from the behavior of both the pure PZT filler and the pure PDC matrix, respectively (Table 1). In comparison to the pure matrix material, no crystallization of the amorphous PDC into cristobalite or another crystalline Si-containing phase is observed. Consequently, the PZT filler is effective at inhibiting the crystallization of the PDC matrix. Compared to the phase evolution of the pure PZT material, the $\mathrm{Pb}\left(\mathrm{Zr}_{x} \mathrm{Ti}_{1-x}\right) \mathrm{O}_{3}$ filler in the PZT-PDC composite is decomposed to a significantly larger extent due to the volatization of $\mathrm{PbO}$. This is manifested in both a higher amount of formed $\mathrm{ZrO}_{2}$ with $81 \mathrm{wt}$ \% and a smaller weight fraction of residual tetragonal $\mathrm{Pb}\left(\mathrm{Zr}_{x} \mathrm{Ti}_{1-x}\right) \mathrm{O}_{3}$ of 19 wt.\% (Table 1). In addition, the $\mathrm{Pb}\left(\mathrm{Zr}_{x} \mathrm{Ti}_{1-x}\right) \mathrm{O}_{3}$ phase is significantly more depleted in $\mathrm{Zr}$ with a $\mathrm{Zr}$ content $x$ of 0.095 . With respect to Equation (2), this is equivalent to a conversion factor $z$ of 0.45 . Again, the phase composition estimated by Equation (2) differs from the actual Rietveld results, which could be explained by the formation of significant amounts of non-crystalline material.

From the XRD investigations, no direct proof of the formation of (crystalline) ternary oxide phases containing $\mathrm{ZrO}_{2}$ or $\mathrm{TiO}_{2}$ from the PZT filler and $\mathrm{SiO}_{2}$ from the PDC matrix is found. Nevertheless, a distinct interaction between the decomposing PZT filler and the PDC matrix at an elevated temperature can be deduced from the finding of a retarded crystallization of $\mathrm{SiO}_{2}$ in the PDC matrix, on the one hand side, and an increased rate of decomposition for the PZT filler, on the other. It is likely that the formation of silica-titania composites is the driving force of both, the increased decomposition of PZT, and the inhibited crystallization of $\mathrm{SiO}_{2}$ from the PDC matrix. However, additional experiments, especially for a structural elucidation of the amorphous parts of the PZT-PDC composites, such as solid-state nuclear magnetic resonance (NMR) measurements, and/or vibrational spectroscopy, are necessary.

\subsection{Mechanical and Thermal Properties of PZT-Polymer Composites}

The bending strength of the pure $\mathrm{H} 62 \mathrm{C}$ polymer after curing at $200{ }^{\circ} \mathrm{C}$ is $31 \mathrm{MPa}$, which is in good agreement to data from the manufacturer (30 MPa after curing at $150{ }^{\circ} \mathrm{C}$ for $16 \mathrm{~h}$; Wacker Chemie AG). The bending strength of the pure PZT filler sintered at $1250{ }^{\circ} \mathrm{C}$ is $43 \mathrm{MPa}$. This is significantly lower than the values from the literature ranging between $60 \mathrm{MPa}$ and $86 \mathrm{MPa}$ for polycrystalline PZT ceramics $[25,26]$. The reason for this is most likely the partial decomposition of the PZT material during the sintering conditions resulting in the formation of porosity, on the one hand, and of significant 
amounts of zirconia, on the other. Large amounts of $\mathrm{ZrO}_{2}$ within the microstructure of PZT ceramics exceeding $10 \mathrm{vol} . \%$ are known to reduce their strength by approximately $50 \%$ due to the formation of microcracks [27].

The bending strength of the PZT-polymer composites after curing at $200{ }^{\circ} \mathrm{C}$ ranges between $20 \mathrm{MPa}$ and $29 \mathrm{MPa}$, whereas no direct correlation with the PZT load is observed (Figure 6). The strength of the composite material with the highest PZT content of 55 vol.\% should be considered as an outlier as the homogenization of the PZT-H62C mass was considerably hindered due to the high solid content of the mixture. This finding is in good accord with the porosity of the sample with $55 \mathrm{vol} \%$ PZT, which is the highest value in the sample series with 5.6 vol.\%.

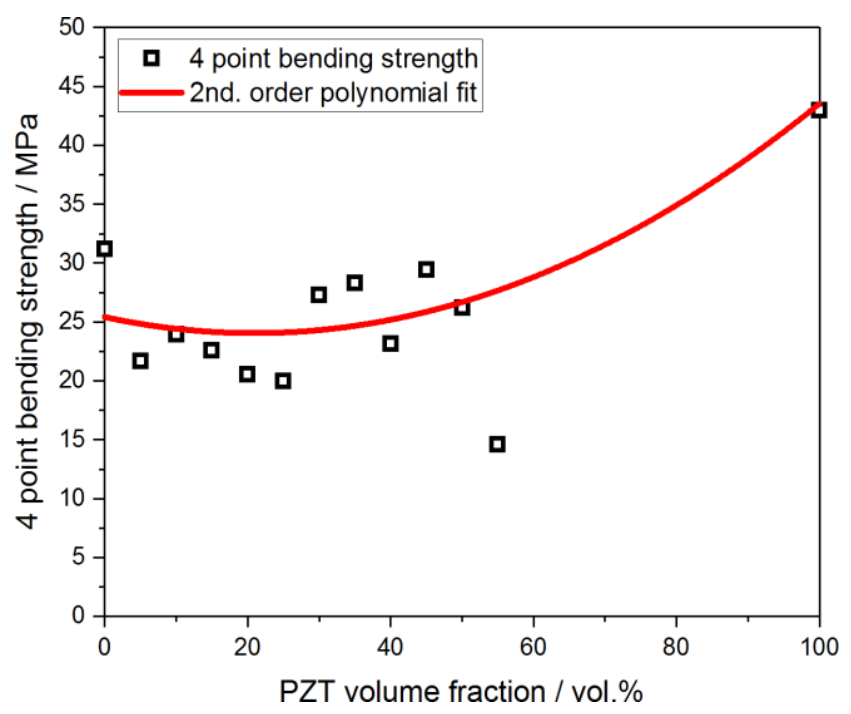

Figure 6. Four-point bending strength of PZT-polymer composites cured at $200{ }^{\circ} \mathrm{C}$ as a function of the filler content.

The thermal conductivity $\lambda$ of the pure $\mathrm{H} 62 \mathrm{C}$ polymer after curing at $200{ }^{\circ} \mathrm{C}$ is $0.14 \mathrm{~W} \cdot \mathrm{m}^{-1} \cdot \mathrm{K}^{-1}$, which is in good agreement with data from the manufacturer $\left(0.2 \mathrm{~W} \cdot \mathrm{m}^{-1} \cdot \mathrm{K}^{-1}\right.$ after curing at $150^{\circ} \mathrm{C}$ for $16 \mathrm{~h}$; Wacker Chemie AG). For the pure PZT material, after sintering at $1250{ }^{\circ} \mathrm{C}$, a $\lambda$ of $0.81 \mathrm{~W} \cdot \mathrm{m}^{-1} \cdot \mathrm{K}^{-1}$ is found, which is lower compared to the literature data of $1.2 \mathrm{~W} \cdot \mathrm{m}^{-1} \cdot \mathrm{K}^{-1}$ for the room temperature thermal conductivity of pure PZT [28]. Consequently, the thermal conductivity of the PZT-polymer composites after curing at $200{ }^{\circ} \mathrm{C}$ steadily increases from $0.18 \mathrm{~W} \cdot \mathrm{m}^{-1} \cdot \mathrm{K}^{-1}$ for the sample with $5 \mathrm{vol} . \%$ PZT filler to $0.36 \mathrm{~W} \cdot \mathrm{m}^{-1} \cdot \mathrm{K}^{-1}$ for the specimen containing $50 \mathrm{vol}$ \% PZT (Figure 7 ). Furthermore, the thermal conductivity of the PZT-polymer composites could be satisfactorily modelled by Landauer's theory of effective percolation with $\lambda_{\text {matrix }}=0.14 \mathrm{~W} \cdot \mathrm{m}^{-1} \cdot \mathrm{K}^{-1}$ and $\lambda_{\text {filler }}=0.81 \mathrm{~W} \cdot \mathrm{m}^{-1} \cdot \mathrm{K}^{-1}$. The specimen with 55 vol.\% PZT filler should be considered as an outlier due to the difficulties in the homogenization of the starting materials. 


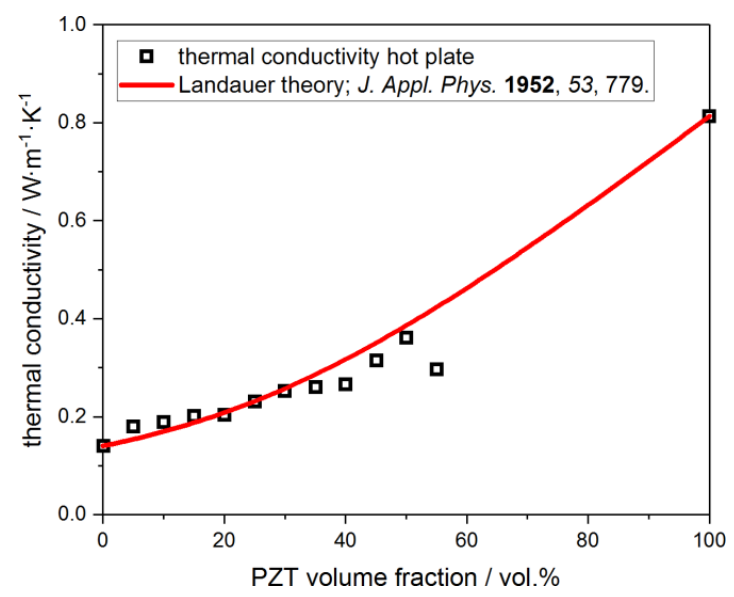

Figure 7. Experimental thermal conductivity (hot plate technique) of PZT-polymer composites cured at $200{ }^{\circ} \mathrm{C}$ as a function of the filler content. The observed data ( $\square$ ) fits well to the values extrapolated by the Landauer theory (red line).

\subsection{Piezoelectric Properties of PZT-Polymer Composites}

The relative permittivity $\varepsilon_{\mathrm{R}}$ of the samples increases exponentially with an increasing amount of PZT material (Figure 8a). For the pure polymer matrix, a low $\varepsilon_{R}$ of 2.34 is the result, which increases to 1195 for the pure PZT filler. The course of $\varepsilon_{R}$, with the increasing volume fraction of PZT filler, is predicted satisfactorily by both the Yamada model for oriented anisotropic particles but without particle-particle interaction [10] and the model of Jayasundere, which assumes spherical particles, but includes interactions between the filler particles [11]. The simple Lichtenecker rule of mixture overestimates the permittivity of the composite for filler contents above $30 \mathrm{vol} . \%$. The longitudinal charge constant $\mathrm{d}_{33}$ increases almost linearly from $0.03 \mathrm{pC} \cdot \mathrm{N}^{-1}$ for the PZT-polymer composite with 5 vol.\% PZT filler to a value $0.77 \mathrm{pC} \cdot \mathrm{N}^{-1}$ for the sample with 55 vol.\% PZT content (Figure $8 \mathrm{~b}$ ), and the pure PZT filler gives a $\mathrm{d}_{33}$ of $400 \mathrm{pC} \cdot \mathrm{N}^{-1}$, which is in good agreement with the specifications of the manufacturer (443 $\mathrm{pC} \cdot \mathrm{N}^{-1}$; Noliac Ceramics s.r.o.). The course of the $\mathrm{d}_{33}$ constant as a function of the PZT load is sufficiently modelled with the models of Yamada and Jayasundere as well. Nevertheless, the results for the longitudinal charge constant for the PZT-polymer composites are significantly lower compared to data for PZT-PDMS composites with similar filler loads. For these, a maximal $\mathrm{d}_{33}$ of $25 \mathrm{pC} \cdot \mathrm{N}^{-1}$ at a filler load of $50 \mathrm{vol} . \%$ has been observed [13]. Most likely, this is a consequence of the different sample geometry (thin films rather than bulk specimens) and the polarization, which was performed at a higher field strength of $12 \mathrm{kV} \cdot \mathrm{mm}^{-1}$ compared to $2 \mathrm{kV} \cdot \mathrm{mm}^{-1}$ within the present work.

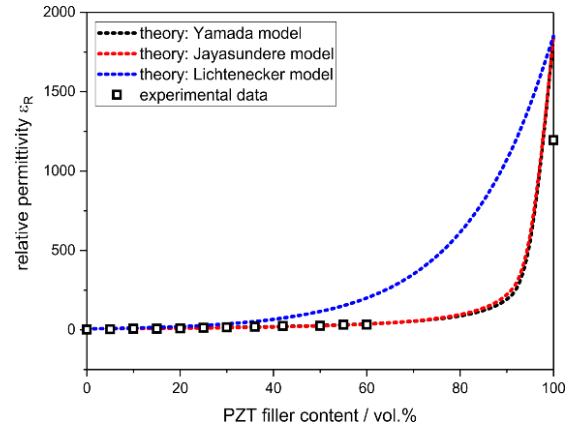

(a)

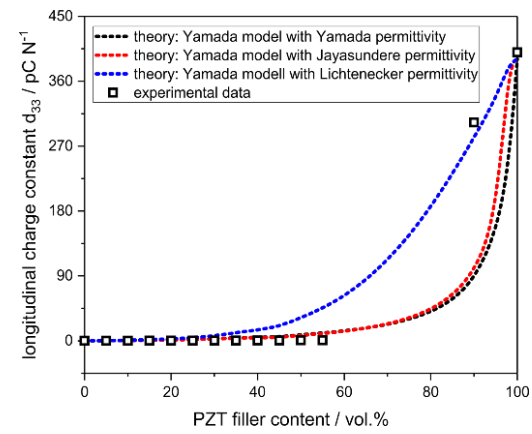

(b)

Figure 8. Experimental results for the relative permittivity (a) and the piezoelectric charge constant $d_{33}$ (b) of PZT-polymer composites, the pure polymer matrix, and the pure PZT filler. The experimental data could be modelled sufficiently using the models of Yamada and Jayasundere for the extrapolation of the permittivity and $d_{33}$ data. 


\section{Conclusions}

The main goal of the present work was to show the feasibility of a preceramic polymer as a suitable matrix phase for PZT-polymer composites. It could be shown that the manufacturing of composites with lead zirconate titanate (PZT) as functional filler phase and a silsesquioxane polymer as thermally curable matrix phase is possible. A filler load of $55 \mathrm{vol} \%$, which is approximately $90 \mathrm{wt} . \%$, could be achieved. The mechanical strength of the PZT-polymer composite materials ranging between 15 and $29 \mathrm{MPa}$ was slightly lower than that of the pure matrix and the filler materials and correlated with the degree of homogenization of the starting components. The composite's thermal conductivity is a direct function of the filler load according to Landauer's theory of effective percolation, lying in between the values for the pure matrix material and the PZT filler, respectively. The thermal stability of the PZT-PDC composites has been proven up to a temperature of $750{ }^{\circ} \mathrm{C}$; higher temperatures result in the decomposition of the PZT filler under the volatization of $\mathrm{PbO}$ and formation of $\mathrm{ZrO}_{2}$. From XRD studies, an inhibition of the crystallization of the PDC matrix in the presence of the PZT filler has been observed; conversely, the embedment of PZT into the PDC matrix results in a pronounced decomposition of the filler compared to the pure PZT material. This effect has been observed for other silicon-based PDCs with inorganic fillers as well as, for example, in composites of SiOC as a matrix phase and $\mathrm{LiAlSiO}_{4}$ ( $\beta$-eucryptite) or $\mathrm{ZrW}_{2} \mathrm{O}_{8}$ (zirconium wolframate) as fillers [29,30]. As an analogy to this study, the formation of $\mathrm{SiO}_{2}$ from the PDC matrix has been accounted for the influence on the phase stability of the respective inorganic filler phase. The piezoelectric properties of the composite materials are very limited with low values of the piezoelectric charge and voltage parameters $d_{33}$ and $\mathrm{g}_{33}$, respectively. Essentially, this is a consequence of the polarization procedure, performed at a lower field strength compared to similar composites.

In sum, this study was intended as a proof of principle for the successful incorporation of a PZT filler into a preceramic polymer or into the respective SiOC PDC matrix generated therefrom. Future studies should be aimed at the investigation of effects related to the degree of crosslinking in the preceramic polymer, which could be modified by the crosslinking temperature and duration, on the one hand side and the role and composition of the amorphous phase formed during the matrix-induced decomposition of the PZT filler. These effects could then be correlated to the properties of this class of composites, resulting in a more comprehensive understanding of the structure-property relations in this material system.

Supplementary Materials: The following are available online at http://www.mdpi.com/1996-1944/13/7/1520/s1, Figure S1: SEM micrographs of PZT-polymer composites with increasing filler content (dark: polymer matrix, bright: filler particles); (a) 5 vol.\% PZT, (b) 15 vol.\% PZT, (c) 25 vol.\% PZT, (d) 35 vol.\% PZT, (e) 45 vol.\% PZT, (f) 55 vol.\% PZT, Figure S2: SEM micrographs of selected PZT-polymer composites with a filler content of 40 vol.\% PZT with increasing heat treatment processing; (a) $500{ }^{\circ} \mathrm{C}$, (b) $750{ }^{\circ} \mathrm{C}$, (c) $1000{ }^{\circ} \mathrm{C}$, (d) $1250{ }^{\circ} \mathrm{C}$, Figure S3: Particle size distribution of the PZT powder used within this study.

Author Contributions: For this work, T.F. conceived and designed the experiments; S.K. and F.E. performed the experiments; F.E., U.B. and T.F. analyzed the data; and T.F. and U.B. wrote the paper. All authors have read and agreed to the published version of the manuscript.

Funding: This research received no external funding.

Acknowledgments: The authors like to acknowledge the Emerging Fields Initiative of Friedrich-Alexander-University Erlangen-Nürnberg for financial support in the project "Mojo 3D".

Conflicts of Interest: The authors declare no conflict of interest.

\section{References}

1. Babu, I.; van den Ende, D.A.; de With, G. Processing and characterization of piezoelectric 0-3 PZT/LCT/PA composites. J. Phys. D Appl. Phys. 2010, 43, 425402. [CrossRef]

2. Salmang, H.; Scholze, H.; Telle, R. Keramik, 7th ed.; Springer: Berlin/Heidelberg, Germany, 2007.

3. Jaffe, B.; Cook, W.R.; Jaffe, H. Piezoelectric Ceramics; Academic Pr: London, UK, 1971.

4. Seifert, K.; Schlegel, T.; Rödel, J. Entwicklung neuer oxidischer Piezowerkstoffe. Thema Forschung 2006, 10-13. 
5. Newnham, R.E.; Skinner, D.P.; Cross, L.E. Connectivity and piezoelectric-pyroelectric composites. Mater. Res. Bull. 1978, 13, 525-536. [CrossRef]

6. Konegger, T.; Potzmann, R.; Puchberger, M.; Liersch, A. Matrix-filler interactions in polysilazane-derived ceramics with $\mathrm{Al}_{2} \mathrm{O}_{3}$ and $\mathrm{ZrO}_{2}$ fillers. J. Eur. Ceram. Soc. 2011, 31, 3021-3031. [CrossRef]

7. Sharma, S.K.; Gaur, H.; Kulkarni, M.; Patil, G.; Bhattacharya, B.; Sharma, A. PZT-PDMS composite for active damping of vibrations. Compos. Sci. Technol. 2013, 77, 42-51. [CrossRef]

8. Babu, I.; Hendrix, M.M.R.M.; de With, G. PZT-5A4/PA and PZT-5A4/PDMS piezoelectric composite bimorphs. Smart Mater. Struct. 2014, 23, 25029. [CrossRef]

9. Bhimasankaram, T.; Suryanarayana, S.; Prasad, G. Piezoelectric polymer composite materials. Curr. Sci. 1998, 74, 967-976.

10. Yamada, T.; Ueda, T.; Kitayama, T. Piezoelectricity of a high-content lead zirconate titanate/polymer composite. J. Appl. Phys. 1982, 53, 4328-4332. [CrossRef]

11. Jayasundere, N.; Smith, B.V. Dielectric constant for binary piezoelectric 0-3 composites. J. Appl. Phys. 1993, 73, 2462-2466. [CrossRef]

12. Satish, B.; Sridevi, K.; Vijaya, M.S. Study of piezoelectric and dielectric properties of ferroelectric PZT-polymer composites prepared by hot-press technique. J. Phys. D Appl. Phys. 2002, 35, 2048-2050. [CrossRef]

13. Babu, I.; de With, G. Highly flexible piezoelectric 0-3 PZT-PDMS composites with high filler content. Compos. Sci. Technol. 2014, 91, 91-97. [CrossRef]

14. Greil, P. Polymer Derived Engineering Ceramics. Adv. Eng. Mater. 2000, 2, 339-348. [CrossRef]

15. Furukawa, T.; Fujino, K.; Fukada, E. Electromechanical Properties in the Composites of Epoxy Resin and PZT Ceramics. Jpn. J. Appl. Phys. 1976, 15, 2119-2129. [CrossRef]

16. Landauer, R. The Electrical Resistance of Binary Metallic Mixtures. J. Appl. Phys. 1952, 23, 779-784. [CrossRef]

17. Smith, D.S.; Alzina, A.; Bourret, J.; Nait-Ali, B.; Pennec, F.; Tessier-Doyen, N.; Otsu, K.; Matsubara, H.; Elser, P.; Gonzenbach, U.T. Thermal conductivity of porous materials. J. Mater. Res. 2013, 28, 2260-2272. [CrossRef]

18. Song, B.-M.; Kim, D.-Y.; Shirasaki, S.-I.; Yamamura, H. Effect of Excess PbO on the Densification of PLZT Ceramics. J. Am. Ceram. Soc. 1989, 72, 833-836. [CrossRef]

19. Vegard, L. Die Konstitution der Mischkristalle und die Raumfllung der Atome. Z. Physik 1921, 5, 17-26. [CrossRef]

20. Frantti, J.; Lappalainen, J.; Eriksson, S.; Lantto, V.; Nishio, S.; Kakihana, M.; Ivanov, S.; Rundlöf, H. Neutron Diffraction Studies of $\mathrm{Pb}\left(\mathrm{Zr}_{\mathrm{x}} \mathrm{Ti}_{1-\mathrm{x}}\right) \mathrm{O}_{3}$ Ceramics. Jpn. J. Appl. Phys. 2000, 39, 5697-5703. [CrossRef]

21. Joseph, J.; Vimala, T.M.; Sivasubramanian, V.; Murthy, V.R.K. Structural investigations on $\mathrm{Pb}\left(\mathrm{Zr}_{\mathrm{x}} \mathrm{Ti}_{1-\mathrm{x}}\right) \mathrm{O}_{3}$ solid solutions using the X-ray Rietveld method. J. Mater. Sci. 2000, 35, 1571-1575. [CrossRef]

22. Mastelaro, V.R.; Doriguetto, A.C.; Neves, P.P.; Garcia, D.; Lente, M.H.; Mascarenhas, Y.P.; Michalowicz, A.; Eiras, J.A. Structural Characterization of $\mathrm{Pb}_{1-\mathrm{x}} \mathrm{Ba}_{\mathrm{x}} \mathrm{Zr}_{0.65} \mathrm{Ti}_{0.35} \mathrm{O}_{3}$ Ferroelectric Ceramics. Ferroelectrics 2011, 339, 219-226. [CrossRef]

23. Glazer, A.M.; Mabud, S.A. Powder profile refinement of lead zirconate titanate at several temperatures. II. Pure $\mathrm{PbTiO}_{3}$. Acta Crystallogr. Sect. B Struct. Crystallogr. Cryst. Chem. 1978, 34, 1065-1070. [CrossRef]

24. Yokota, H.; Zhang, N.; Taylor, A.E.; Thomas, P.A.; Glazer, A.M. Crystal structure of the rhombohedral phase of $\mathrm{PbZr}_{1-\mathrm{x}} \mathrm{Ti}_{\mathrm{x}} \mathrm{O}_{3}$ ceramics at room temperature. Phys. Rev. B 2009, 80, 104109. [CrossRef]

25. Fett, T.; Munz, D.; Thun, G. Tensile and bending strength of piezoelectric ceramics. J. Mater. Sci. Lett. 1999, 18, 1899-1902. [CrossRef]

26. Fett, T.; Munz, D.; Thun, G. Bending strength of a PZT ceramic under electric fields. J. Eur. Ceram. Soc. 2003, 23, 195-202. [CrossRef]

27. Malič, B.; Kosec, M.; Kosmač, T. Mechanical and electric properties of $\mathrm{PZT}-\mathrm{ZrO}_{2}$ composites. Ferroelectrics 1992, 129, 147-155. [CrossRef]

28. Kallaev, S.N.; Gadzhiev, G.G.; Kamilov, I.K.; Omarov, Z.M.; Sadykov, S.A.; Reznichenko, L.A. Thermal properties of PZT-based ferroelectric ceramics. Phys. Solid State 2006, 48, 1169-1170. [CrossRef] 
29. Fedorova, A.; Betke, U.; Scheffler, M. Polymer Derived Ceramics with b-Eucryptite Fillers: Filler-Matrix Interactions. Adv. Eng. Mater. 2017, 19, 1700079. [CrossRef]

30. Fedorova, A.; Scheffler, M. Polymer Derived Ceramics with Negative Thermal Expansion Fillers: Zirconium Tungstate. Adv. Eng. Mater. 2019, 21, 1900116. [CrossRef]

(C) 2020 by the authors. Licensee MDPI, Basel, Switzerland. This article is an open access article distributed under the terms and conditions of the Creative Commons Attribution (CC BY) license (http://creativecommons.org/licenses/by/4.0/). 